\title{
Mecanismos de regulación internacional de productos básicos
}

\begin{abstract}
Frangisco VILLAgrán KraMer, Jurista y politicólogo guatemalteco, fue diputado en el Congreso de su país $y$ profesor de la Universidad de San Carlos. Ha publicado Asile diplomatique d'après la practique des Etats Latinoaméricains, Casos $y$ documentos de Derecho Internacional e Integracion Centroamericana. Actualmente es profesor de la Universidad de El Salvador.
\end{abstract}

Las prolongadas negociaciones a que dan lugar los productos básicos a nivel internacional no sólo revelan la complejidad de la comercialización, sino una marcada tendencia a una regulación producto por producto que enfrente a los países en vías de desarrollo con los países industrializados, y lo que es más importante, a los países del Tercer Mundo entre sí, dando lugar a que no exista actualmente uniformidad en esta materia sino, por el contrario, diversidad de regimenes.

Es importante por ello precisar las grandes variantes que se dan en el plano internacional respecto a la regulación de los productos básicos, así como las modalidades concretas de comercialización y la incidencia de tales regímenes en los programas nacionales de desarrollo, y en las políticas de alineación de los países del Tercer Mundo.

Para ello, se parte del hecho que, con excepción del café, cacao, caucho, bananos, té y otros productos de menor volumen y significación en el comercio internacional, otros productos básicos exportados por los países en vías de desarrollo, son asimismo producidos y exportados por los países altamente industrializados, y aquellos otros que engrosan esa categoría, aunque no la potencialidad y con lo que la posición de negociación de los países del Tercer Mundo frente a los países desarrollados se ve en cierta forma afectada.

De reducir el espectro de nuestro análisis al campo meramente institucional implicaría vernos limitados al estudio de los instru- 
mentos convencionales - tratados y convenios- que regulan determinados productos básicos, particularmente, azúcar, café, cacao, trigo. De ahí que optaremos por ampliar el espectro, ubicando el problema, o la gama de problemas, dentro de un contexto económico, político y jurídico, situándonos, de consiguiente, en el contexto real en el cual ocurren los fenómenos. Tal metodología da lugar, por lo demás, al examen de otros problemas interrelacionados.

Huelga decir que nuestra tarea en cierta forma se complicó, al vernos obligados, por la metodología seguida, a hacer correlaciones con la serie de productos básicos en los cuales los países americanos tienen interés directo. Afortunadamente esa labor se simplificó en gran parte al contar con la valiosa ayuda de FAO y sus publicaciones más recientes, e, igualmente, de UNCTAD y la Comunidad Económica Europea - CEE-, cuyos documentos e informes usamos generosamente.

A efectos de deslindar el terreno, creemos oportuno traer a cuenta que desde la perspectiva de los países en desarrollo, el término "productos básicos" comprende tanto los de naturaleza agrícola y pecuaria, como los hidrocarburos y minerales, al constituir el rubro más importante de sus exportaciones y el renglón de mayor significación en sus balanzas de pagos, mientras para los países industrializados, el término designa preferentemente los productos agrícolas y pecuarios en razón de su número y su propia naturaleza, y por el hecho de que el número de países participantes en el comercio mundial es mayor tratándose de estos que de los hidrocarburos y minerales. Este concepto restringido prevalece en el plano internacional.

\section{PARAMIETROS DE REFERENGIA}

La incidencia de los productos básicos en las economías de los países subdesarrollados y, en particular, de los países americanos, es no sólo significativa sino que, a la par, estos tienen una relevancia igualmente importante en el comercio mundial. Los rubros clasificados por FAO: cereales (trigo, cereales secundarios y arroz); productos pecuarios, aceites y tortas oleaginosas; productos alimentarios (azúcar, bananos, cítricos, uvas, frutas secas y pimienta); bebidas y tabaco (café, cacao, té, vino y tabaco) y las materias primas agrícolas (algodón, lana, yute, kenaf y fibras afines, fibras duras, caucho natural y cueros y pieles), ofrecen un cuadro a cual más revelador en el que aparecen, por su orden de importancia, en relación a volumeri y precios, en primer término, el trigo y las grasas y aceites; luego el café, azúcar, algodón, y de ahí los restantes productos. El cuadro nú- 
mero uno proporciona a este respecto, una idea más concreta y clara, destacándose las extrạordinarias cantidades. a que asciende el comercio internacional de trigo (más de tres billones de dólares USA); el café (cerca de tres billoneses), azúcar y algodón, más de dos billones de dólares y la lana y caucho más de un billón de dólares. De todos los productos básicos, incluyendo los hidrocarburos y minerales, únicamente el petróleo y sus derivados sobrepasan los de naturaleza agrícola y pecuaria,

Con respecto a la participación de los países subdesarrollados de América en el comercio mundial de los principales productos básicos, convendría tener presente los siguientes indicadores:

Trigo: Argentina y México en su calidad de. productores, y los restantes consumidores (importadores).

Café: Brasil, Colombia, Costa Rica, EI Salvador, Guatemala, México, Perú y Venezuela, y con tendencia a aumentar su participación en el mercado mundial, Honduras, Nicaragua, Cuba, República Dominicana, Trinidad y Tobago y Jamaica.

Azúcar: Cuba, República Dominịcana, Trinidad y Tobago, Jamaịca, Barbados, Guyana, Perú, México, Guatemala, El Salvador, Honduras, Nicaragua, Costa Rica, Panamá, Venezuela y Colombia.

Algodón: Brasil, México, Nicaragua, Guatemala, El Salvador, Costa Rica, Colombia, Perú y Argentina.

Cacao: Brasil (mayor productor), Costa Rica y Mréxico.

Lana: Argentina y Uruguay.

Caucho: Brasil, Guatemala, Perú, Colombia y Venezuela.

Bananos: Ecuadọ, Panamá, Costa Rica, Honduras, Guatemala, Jamaica, Trinidad y Tobago, Barbados.

Hidrocarburos: Venezuela, Trinidad y Tobago, y Ecuador con mayores posibilidades de intervención.

Minerales: Bolivia, Chile, Venezuela, República Dominicana, Costa Rica, Cuba, Perú.

La anterior descomposición por productos y países permite observar que la participación de los países americanos en los mecanismos de comercio internacional no es homogénea, y que, en razón del factor competencia, existen si no antagonismos, en todo caso, posiciones conflictivas; mas en conjunto, puede decirse que la participación de dichos países es más relevante en el caso del café (con fuerte acento de Brasil. y Colombia), y luego, en el algodón y el azúcar; de ahí que el café resulte ser el producto básico que más interés presenta para la América subdesarrollada en conjunto.

Como se sabe, el comercio agropecuario mundial aumentó en los años 1971 y 1972, aproximadamente en un cuatro por ciento, pero tales aumentos, en el volumen de las exportaciones, en términos generales, fueron acompañados de precios más bajos, y sólo en algunos casos el aumento del volumen del comercio se tradujo en 
incrementos en el valor de las exportaciones, mientras en otros -el caso del café-, ocurrió una disminución en el volumen del comercio mundial, registrándose precios más altos.

EI hecho, sin embargo, es que, conforme al Informe de FAO, "Situación y Perspectivas de los Productos Básicos 1971-72 (liberado el 9 de octubre de 1972)", "Ias exportaciones de productos agropecuarios de los países en desarrollo sufrieron una disminución de aproximadamente el tres por ciento (alrededor de 410 millones de dólares de Estados Unidos) en contraste con el aumento del once por ciento experimentado por la de los países desarrollados. Eso se debió en gran parte a la viva competencia por los mercados de los productos que presentan gran interés para ellos desde el punto de vista de las exportaciones." 1

Al trasladarse al terreno de las perspectivas, a más largo plazo, no puede desconocerse, como lo señala FAO, que los saldos netos del comercio (exportaciones f.o.b. menos importaciones c.i.f.) por regiones, "muestran que las exportaciones netas de los países en desarrollo en 1960-70, aumentaron à un ritmo anual de 1.1 por ciento solamente. Por tanto, el comercio de los productos agiopecuarios hizo una contribución nada más que modesta a sus ingresos de divisas en el último decenio". Pero, luego se agrega: "Las importaciones netas de los países desarrollados en ese mismo período, aumentaron a un ritmo anual de 3.6 por ciento." Los países de planificación económica centralizada aumentaron sus importaciones netas de productos agropecuarios en casi un 19 por ciento aunque su participación en el total mundial siguió siendo pequeña. Los cambios más espectaculares fueron el brusco incremento de las importaciones netas de productos agropecuarios de los "demás países desarrollados", (principalmente Japón) y el fuerte descenso de las exportaciones netas de dichos productos de Asia y el Lejano Oriente 2 . El cuadro NNo 2, ilustra con más detalles lo antes expuesto.

El marco de análisis inicial quedaría incompleto al soslayarse el hecho de que la participación de los países desarrollados, vale decir, industrializados, en el comercio mundial de los productos básicos tiende a aumentar a ritmos más veloces que la participación de los países en vías de desarrollo, amén de que el comercio entre los propios países industrializados, a su vez, registra indices de aumento más apreciables que el de los países subdesarrollados con los países industrializados. El más reciente testimonio, y que confirma lo expuesto, está constituidó por las negociaciones entre la Unión Sovié-

${ }^{1}$ FAO, Situación y perspectivas de los Productos Básicos, 1971-1972, Roma. Organización de las Naciones Unidas para la Agricultura y la Alimentación, 1972, p. I (en adelante citado únicamente como "FAO").

'FAO, op. cit., p. 20. 
tica y Estados Unidos en relación a cereales (trigo, etc.) ; las negociaciones para estabilizar el comercio de productos agrícolas entre Estados Unidos, Canadá y los países socialistas con la Comunidad Económica Europea, y la compra de productos lácteos por la Unión Soviética a algunos países de la Comunidad, autorizada en el mes de abril de 1973, por la Comisión de las Comunidades Europeas.

Es así como los países en desarrollo se ven compelidos a buscar nuevas alternativas que compensen las disparidades visibles y tangibles que se presentan en el comercio mundial de sus productos básicos, frente al creciente comercio de muchos de dichos productos básicos, entre los países desarrollados y frente al problema que significa la merma del valor real de los ingresos provenientes de las exportaciones agrícolas. Esto último, se pone de manifiesto al tenerse presente que el poder.adquisitivo real de las exportaciones agricolas no aumentó de manera apreciable, y que, en el caso de los países en desarrollo, "el poder adquisitivo de sus exportaciones agrícolas disminuyó por haberse deprimido los precios de sus principales productos de exportación, mientras subieron los precios de las manufacturas, que constituyen sus principales importaciones"3. Debe aún agregarse, que en ciertos casos, como el trigo, una sola operación efectuada a nivel de países desarrollados (Estados Unidos y la Unión Soviética) resultó afectando el nivel de precios para los países subdesarrollados importadores de dicho cereal, sin beneficiar, apreciable y correlativamente, a otros países en vías de desarrollo productores de trigo, cual el caso de Mréxico y Argentina.

La dimensión y complejidad del problema, o la suma de problemas si se prefiere, plantea a la comunidad internacional, y principalmente a los países en desarrollo, la búsqueda de fórmulas y mecanismos para elevar el índice de aumento de las exportaciones de los países en desarrollo, a fin de dar una contribución más apropiada al bienestar de sus pueblos, y restablecer, aunque en parte, el creciente desequilibrio que existe, y que ahonda la brecha entre los desarrollados y los subdesarrollados.

Hasta el presente, puede decirse que las expectativas de los países latinoamericanos, incluyendo a los países independientes del Caribe, se han orientado en dirección de la búsqueda de nuevos mercados, entendiéndose por tales, principalmente, los países de economía

${ }^{3} \mathrm{FAO}$, Ibid. Téngase, además, presente las dos devaluaciones del dólar US que afectaron sensiblemente a los paises latinoamericanos, y que ha dado lugar a planteamientos de los países productores de café respecto a posíbles fórmulas de reintegro o resarcimiento de pérdida resultante de devaluaciones monetarias. En adición a ello, el régimen de monedas flotantes puesto en ejecución por Italia, Reino Unido y Japón, en esta misma forma, afecta directamente a los países productores. 
centralizada y dirigida (campo socialista). Mas sobre el particular, no puede ignorarse que tal fórmula está condicionada a sistemas bilaterales y al juego de la reciprocidad, así como, limitada por el hecho de que los países socialistas tienden a aumentar su intercambio con los miembros de la Comunidad Económica Europea, a través de mecanismos en vías de institucionalización, y con Ganadá y Estados Unidos.

Otros países del Tercer Mundo, como los africanos, se orientan en dirección de una mayor alineación económica, ampliando los marcos de interrelación con la Comunidad Económica Europea, y buscando, paralelamente, mayores efectos a las preferencias arancelarias con países europeos no miembros de la CEE, Estados Unidos, Canadá, Australia y Japón. Todo esto constituye un nuevo elemento económico-político en el actual panorama del comercio mundial, que nos obliga a analizarlo, y establecer en qué forma, los países latinoamericanos pueden compatibilizar sus propias estrategias con esas tendencias, puntos de relevancia a los que nos referiremos más adelante. Desde luego, el régimen de preferencias sigue constituyendo un pilar común para los países del Tercer Mundo, pese a que tal política se encuentra, por lo que a los principales productos básicos de interés para Latinoamérica se refiere, dentro de los marcos del GATT, y relacionada estrechamente con los regímenes de tipo convencional sobre productos básicos existentes a la fecha.

Los países en vías de desarrollo han aceptado esta última modalidad y por lo que han pugnado y continúan con la estrategia de buscar la regulación del comercio de determinados productos básicos vitales para sus economías a través del sistema de convenios internacionales especializados por productos, cual el caso del café, azúcar, cacao, etc., en los que participan como productores, y en otros, como el trigo, lo hacen, unos como productores, y otros como consumidores.

De esta suerte, se busca una mesa de negociaciones separada por productos, y no una mesa de negociaciones general que pudiere, incluso, dar lugar a negociaciones producto por producto.

Puede decirse que las anteriores fórmulas conllevan estrategias definidas, y dentro de ellas, puede ubicarse la modalidad de meca-

*Téngase presente que Hungria solicitó acceder al GATT, y que el creciente intercambio comercial entre los paises del COMECON y la Comunidad Económica Europea tiende a ser mayor que el de los países del COMECON con el Tercer Mundo. En adición, consúltense el excelente estudio de TOLEDADO LAREDO, Armando: "LA PARTICIPAZIONE DELIA G.E.E. AGLI ACCORDI INTERNAZIONALI E L'ATTEGGIAMENTO DEI PAESI DEL COMECON", Revista "Il Diritto negli scambi internazionali", No 2, julio 1972, SEDIT, pp. I51-171. 
F. Tillagrán Kramer / Mecanismos de regulación internacional de productos básicos

nismos de defensa que implican no una intervención directa en el comercio mundial por parte del Estado, sino sobre todo, suprimir, o reducir el efecto de los intermediarios en el comercio mundial. Entre estas fórmulas, destacan las variantes del comercio de Estado y la Organización de Países Productores de Petróleo (OPEP).

Procede, pues, aproximarnos a estos problemas desde la perspectiva institucional.

\section{MECANISMOS INSTITUCIONALES A NIVEL INTERNAGIONAL}

\section{Las grandes variantes}

Resulta significativo que los productos básicos con volumen apreciable de comercio, cuantitativamente y a nivel de precios, hayan dado lugar en el pasado inmediato a la institucionalización de mecanismos de tipo convencional en el plano internacional. Los convenios relativos al trigo, café, azúcar, cacao, aceite de oliva ilustran el punto expuesto, debiéndose recordar que, por su parte, estos productos tienen una alta significación desde el punto de vista de ingresos derivados de la exportación, para los países subdesarrollados, y una mayor relevancia, desde el punto de vista social, por cuanto afectan los niveles salariales en los distintos países productores. Estos productos, pues, han motivado que su comercialización en el plano mundial se ajuste a convenios internacionales de tipo abierto en los que, aparte de la fijación de asignaciones o cuotas a los países productores, se persigue estimular el aumento del consumo en los países consumidores.

Luego, tratándose de otro tipo de productos básicos, los granos básicos fundamentalmente, que juegan un papel importante en los requerimientos alimenticios, se ha acentuado el fenómeno de la regionalización, vale decir, mecanismos de tipo regional que se dan principalmente dentro de esquemas de cooperación o integración económica, cual el caso del mercado común de los productos agrícolas en la CEE, el régimen de granos básicos en el mercado común centroamericano y que, por tal circunstancia, su comercialización se ajusta a pautas un tanto distintas a las de los productos básicos que se han regulado por convenios internacionales de tipo mundial.

Finalmente, los restantes se regulan dentro de marcos intergubernamentales, cual el caso de los Grupos Intergubernamentales o Comités Estadísticos o de Consulta que accionan en estrecha relación con las agencias especializadas de Naciones Unidas (FAO princi- 
palmente), y que se han abierto recientemente al foro mundial que constituye la UNCTAD. 5

Estamos, pues, a presencia de tres grandes variantes de regulación, siendo la primera, la que presenta mayor interés para los países en vías de desarrollo, y en la que, a su vez, existe un grado mayor de conflictos resultantes de la competencia entre los propios países en vías de desarrollo, por cuanto, con excepción del trigo, el aceite de oliva y el azúcar, los otros productos son originarios de los países subdesarrollados, es decir, son exportados por éstos.

\section{El equilibrio, como nota dominante}

Las tres grandes variantes tienen elementos en común, y a la par diferencias. De esta manera, tanto los mecanismos de carácter convencional a nivel mundial, que sobresalen por la activa participación de productores y consumidores, como los que se dan a nivel de esquemas de integración económica y estructuras intergubernamentales de tipo consultivo o cooperativo, no persiguen suprimir el principio de la oferta y la demanda, como regulador básico del comercio internacional (o regional) sino, fundamentalmente, establecer mecanismo paca asegurar, en la mayor medida posible, un equilibrio entre la oferta y la demanda; en otros términos, lograr la institucionalización de un crecimiento equilibrado de la producción, para atenuar los efectos perjudiciales de los desequilibrios bruscos que afectan el intercambio entre productores y consumidores. El fenómeno, por lo demás

${ }^{5}$ Tal el caso del COMITE DE NEGOCLACIONES DE LA UNCTAD, cuya principal actividad consistió en la discusión de un acuerdo sobre el cacao. En cuanto a otros mecanismos, téngase presente el Grupo Intergubernamental sobre el arroz; el Grupo Intergubernamental sobre semillas oleaginosas, aceites y grasas; el Grupo Intergubernamental sobre banano; los Comités Consultivos sobre té; sobre fibras duras; Colocación de excedentes, cuyas actividades están relacionadas con la FAO.

En el caso de otros productos básicos, como el algodón, la estructura intergubernamental es más formal, por cuanto existe el CONSEJO INTERNAGIONAL DEL ALGODON, y del que son miembros principalmente los países productores. En su última Conferencia, Managua, 1972, se lograron avances importantes al inducir a la autodisciplina en la producción y exportación. El caso de Estados Unidos podría decirse ilustra esta situación, por cuanto dicho país acordó una política interna correlacionada con su politica de exportación restringida para no afectar a los paises latinoamericanos productores de esta fibra. Con frecuencia, la representación de un país productor -latinoamericano- es confiada directamente a los representantes de los productores privados; es decir, a los directivos de las entidades nacionales privadas existentes en el país, o bien, a funcionarios del Estado, asesorados en dichos eventos - Conferencias Internacionales o reuniones de los comités consultivos-, por los directivos de las entidades privadas. 
se asemeja mucho a lo que acontece a nivel de las economías nacionales, donde predomina la nota estabilizadora de precios, la conservación de stocks y el uso de buffer stocks, los mecanismos de desincentivación e incentivación, premios por calidad, etc., etc.

La tendencia que se perfila, es, entonces, obstruir desequilibrios económicos acentuados que afectan sensiblemente los niveles de precios, y no hacer desaparecer todo tipo de desequilibrios, al punto de anular el principio de la oferta y la demanda, estimulándose, paralelamente, la adopción de políticas a nivel nacional de los países productores para ese efecto, así como, a nivel de países consumidores, para aumentar el volumen de consumo. Se está, pues, a presencia de una tendencia a organizar racionalmente el mercado para beneficio de unos y otros.

La participación de productores y consumidores tiene la ventaja de expeditar o facilitar las negociaciones de organización del mercado, sometiéndolos, en cierta forma, a una disciplina común, que, por lo demás, constituye un nuevo elemento de significación en el comercio internacional, por cuanto incorpora a los países productores, principalmente cuando son subdesarrollados, a la mesa de negociaciones. Ha habido, de consiguiente, una importante traslación de los centros de negociación, y que apareja para los países subdesarrollados mayor accesibilidad a mercados más amplios que anteriormente. ${ }^{6}$

La tendencia a asegurar un crecimiento equilibrado de la produc-

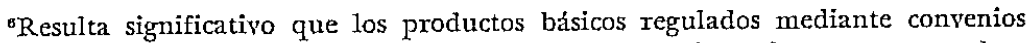
o acuerdos internacionales de tipo abierto, en los que intervienen como productores los países del Tercer Mundo, sean, a su vez, los que han contribuido a mejorar el locus standi de dichos países, cual el caso del café, cacao, azúcar, aceites esenciales. Con ello no afirmamos que el método de regular su comercialización mediante convenios internacionales sea el que mejore el locus standi, sino que este constituye un elemento a cual más importante, al correlacionarlo con el tipo de producto.

EI caso de los hidrocarburos (petróleo y sus derivados), cuya comercialización no se ha regulado mediante convenios internacionales de tipo abierto, sino mediante otro tipo de mecanismos (la organización de los paises productores del petróleo) muestra otro tipo de fenómeno, en relación al locus standi de dichos países productores, que debe correlacionarse con la posición desfavorable en que resultan ubicados otros países del Tercer Mundo, en particular los países latinoamericanos. Es decir, el locus standi de los países productores del petróleo y sus derivados, en cierta medida es a costa de otros países del Tercer Mundo, o en todo caso, repercute no sólo en relación a los países industrializados importadores, sino también, y con mayor profundidad, tratándose de países subdesarrollados importadores. El caso de los países centroamericanos frente a Venezuela, como productor, es revelador del efecto señalado, ya que la balanza comercial $y$ de pagos de los países centroamericanos es desfavorable frente a Venezuela, sin que se vislumbre una atenuación de este fenómeno, más que los arreglos de cooperación económica en el marco caribeño, o de relaciones entre esquemas de integración económica (Pacto Andino y Mercado Común Centroamericano). 
ción mundial obviamente apareja para los países subdesarrollados, no sólo una mayor accesibilidad a nuevos mercados, sino tomar conciencia que tienen capacidad de negociación; aprenden, por ende, a negociar en un nuevo contexto internacional. Este nuevo contexto internacional es mucho más complejo; el análisis o invocación de razones de tipo económico va acompañado de planteamientos políticos, y está induciendo a nuevas alineaciones económico-políticas en el plano mundial, así como a distintas formas de presión, según se trate de un producto u otro (café, azúcar, cacao, etc.) por los países productores sobre los países desarrollados. El solo hecho de que los países importadores desalienten fórmulas de organización entre los países productores basta para confirmarlo, mas la eficacia de tales fórmulas, a su vez, depende de los requerimientos de los países importadores y del hecho que carezcan de otras fuentes de abastecimiento, OPEP, por ejemplo, ilustra una modalidad de presión en el campo internacional; la presión conjunta.

Desde luego, los elementos antes señalados no son comunes a todos los productos básicos, ya que, tratándose del trigo, el hecho de que los países desarrollados sean, a su vez, los principales y mayores productores, no permite imponer una disciplina común a productores y consumidores, punto sobre el cual concurrimos con Tom Farrer, lo que incide en que el mecanismo convencional, lejos de fortalecerse, tienda a debilitarse.

Pero, a la par de los efectos antes señalados, están otros, que siendo comunes a los distintos productos básicos, implican una alteración de importancia en lo que concierne a los intereses económicos, y que se presenta tanto en el plano internacional como en el interno. Nos referimos al nuevo papel que desempeña el Estado.

\section{Grados variables de programación.}

Las tres variantes de institucionalización, persiguen una organización más racional del mercado, sea este el mercado mundial, o un mercado de tipo regional, organización que conlleva la introducción de grados variables de programación o planificación en el plano nacional, a fin de organizar y racionalizar la producción. Las medidas que se acuerdan en el plano internacional, requieren, de consiguiente, de ejecución no sólo en ese plano sino en el interno de cada país, y quedan incompletas de no implementarse a través de políticas $e$ instrumentos nacionales. De ahí que esta otra nota característica, o efecto si se prefiere, de los mecanismos institucionales internacionales haya dado lugar a una nueva modalidad en los sistemas económicos de los países subdesarrollados, y en alguna medida, contri- 
buido a fortalecer sus propios instrumentos de programación del clesarrollo.

Un análisis a lo largo de este último fenómeno permite establecer que la organización del mercado mundial le ha dado al Estado mayor posibilidad de intervenir en la organización de ese mercado, $y$ en el plano nacional, intervención que cobra mayor relevancia según se trate de sistemas de economía de mercado.

El juego abierto a los intereses privados a escala internacional se ha visto en cierta manera restringido por el creciente papel que desempeña el Estado, a la par que ha ofrecido, al propio Estado, una nueva esfera de participación económica, principalmente en aquellas áreas donde los regímenes particulares relativos-a productos básicos, reservan la importación al propio Estado o a la autorización de instituciones estatales, así como, la exportación condicionada a autorizaciones gubernamentales.

La eliminación o atenuación de bruscos desequilibrios, con el consiguiente sistema de asignaciones o cuotas ha, pues, en cierta medida desplazado los intereses privados de esa esfera, y motivado al Estado a intervenir más activamente en ambos planos, convirtiéndolo además, en un órgano ejecutor, en el plano nacional, de los compromisos y deberes que conjuntamente asume con otros a nivel internacional, por cuanto no se limita o restringe, a la ejecución normativa del tratado en el ámbito interno, sino, se extiende a la ejecución, mediante políticas económicas acordes al compromiso internacional. EI régimen de sanciones previsto en el convenio del café, hoy en día en suspenso, nos muestra en abono de esta tesis, que la ejecución de este tipo de convenios no se reduce simplemente a su aprobación o ratificación, y la emisión de instrumentos legales que aseguren su cumplimiento, sino, abarca la adopción e implementación de políticas de producción, y mercado, así como una mayor vigilancia sobre los productores y comerciantes privados.

\section{El nuevo papel del Estado en el comercio mundial}

Como puede apreciarse, estos efectos muestran variaciones de importancia en el régimen tradicional del comercio internacional, que, por largos años, se consideró dominio reservado de los intereses privados, con frecuencia apoyados por sus respectivos gobiernos a través del sistema de una protección diplomática sui generis, o de acuerdos. bilaterales o multilaterales de comercio. La participación del Estado es, pues, hoy en día un hecho que no puede ignorarse.

Al incursionar por estos senderos, nos vemos compelidos a correlacionar este fenómeno con el comercio de Estado. Por ende, ubicados 
en ese contexto, el de la intervención y/o participación del Estado en los mecanismos del comercio mundial, es útil recordar que la esfera de los intereses privados en el comercio mundial si bien se ha visto restringida, no ha sido obstruida, ya que continúa siendo activa a nivel de la producción y de la comercialización de los productos básicos. Este otro hecho, también tiene relevancia en un contexto general del comercio de tales productos.

No viene al caso examinar ambos fenómenos desde la perspectiva de confrontación, por no ser esta la situación real. Podría serlo desde un punto de vista de ideologías, es decir, en un terreno ideológico, mas en todo caso, debe tenerse presente que el sector privado forma parte de la estructura real de poder en los países subdesarrollados, y por lo que el Estado, por lo menos en el plano y desde la perspectiva de nuestro análisis, involucra y representa, a su vez, los intereses de los sectores privados interesados.

De consiguiente, debemos abocarnos al examen de la preocupación del Estado, en el marco del subdesarrollo, frente a los fenómenos que ocurren en el plano internacional. En este campo, la preocupación básicamente es en los países subdesarrollados, de una parte, el deterioro de los términos del intercambio comercial, y de la otra, la merma del ingreso real resultante de sus exportaciones, que afecta directa y fuertemente sus balanzas de pagos, e igualmente, sus programas de desarrollo.

La organización del mercado ha permitido, en alguna medida, cierto equilibrio entre la oferta $y$ la demanda. Si bien no puede llegarse al punto de afirmar que todos los productos básicos han disfrutado de ese beneficio, por lo menos, en cierta medida, los principales productos sí, aunque cuando no se ha logrado superar lo que podría calificarse como las abruptas fluctuaciones resultantes de factores climatéricos que afectan principalmente a los grandes productores (casos de Brasil en relación al café, y de la Unión Soviética en relación al trigo y otros cereales y granos básicos). Tales casos, que tienen carácter excepcional, fuera de toda duda repercuten en los niveles de precios a nivel mundial; pero, también coadyuvan, por ese mismo hecho, a la búsqueda de nuevos mecanismos en los que el Estado desempeña un papel más activo y directo en el comercio internacional.

La organización del mercado, resultante de la institucionalización de mecanismos de tipo convencional, a nivel mundial, regional o sectorial, ha dado como antes se señaló, y conviene traer a cuenta, lugar a una mayor repercusión de las políticas convenidas a nivel internacional, en el plano interno de los países, obligándolos a instrumentar, en ese plano, las políticas de producción que se recomiendan o convienen en un marco internacional, y a establecer 
toda una serie de regulaciones para asegurar el cumplimiento de los compromisos, entre ellas, que el producto exportado se mantenga dentro de los límites de las cuotas o asignaciones convenidas, mas sin producirse un beneficio correlativo en cuanto a los precios $y$ el ingreso real proveniente de las exportaciones.

De contrastarse esta situación, que obriamente afecta a los países en vías de desarrollo, con lo que acontece en el mercado mundial de los productos básicos, en los que los países industrializados intervienen como productores, puede establecerse que, por una parte, el volumen de tales intercambios, a nivel de países desarrollados, no sólo aumenta en forma apreciable, sino que, por la otra, ese aumento va acompañado con mayores ingresos reales, resultantes de las operaciones comerciales.

De consiguiente, no puede negarse que el nivel real de los ingresos de los países productores del mundo subdesarrollado, pese a las regulaciones a que quedan sometidos en virtud de los compromisos o convenios internacionales, y que tienden a garantizarles un crecimiento equilibrado, está lejos de aumentar al mismo ritmo que el volumen de la producción regulada.

De resumir los anteriores elementos de juicio, cabe concluir que los regímenes de organización (mundial, regional o sectorial) del mercado, conducen irremisiblemente a la búsqueda de nuevos sistemas del mercado y distribución de productos básicos, o bien a asociaciones más estrechas de los países productores con los países consumidores, que de por sí implican alineaciones económico-políticas que a la larga, fortalecen el poder de negociación de los países importadores.

III. NUEVOS SISTEMAS DE MERGADEO Y DISTRIBUCIÓN DE PRODUCTOS BÁSICOS

Dentro del contexto de productos básicos el cacao no ocupa un lugar preponderante en relación al trigo, café, azúcar, u otros como el petróleo y sus derivados. Sin embargo, fue precisamente este producto básico, que tiene un alto interés para algunos países africanos, y para pocos países latinoamericanos, el que dio lugar a un replanteamiento del problema de mercadeo y distribución. Los esfuerzos tendientes a normalizar su comercialización, y regular su producción a efectos de ajustarse al sistema general del equilibrio que hemos comentado, tropezaron con múltiples obstáculos. El foro más apropiado para inducir a un examen global del tema, vino a ser la UNCTAD que se reunió en Santiago, Chile, en 1972. 
Dada la importancia de los elementos creemos de utilidad traer a cuenta los principales puntos tratados en el informe que se sometió a consideración de la Conferencia.

\section{Productos básicos y la III UNGTAD}

Se inicia el planteamiento de la Secretaría señalando que toda la cosecha mundial de cacao se produce en países en desarrollo pero es elaborada, transformada en dulces de chocolate y otros productos finales y consumida casi enteramente en el mundo desarrollado. Luego, la existencia de un alto grado de concentración de la propiedad o del control, tanto en los principales países productores como en los paises consumidores. Las compañías que compran el cacao en bruto suelen ser grandes empresas, algunas de ellas gigantescas en relación con las dimensiones de los países productores. ${ }^{7}$

La modalidad generalizada, en cuanto a la producción, podría considerarse que es la fijación de precios que debe pagarse al cultivador; en los países africanos asociados al CEE por medio de las Caisses de Stabilisation y en otios, como Brasil, por el organismo oficial correspondiente. Tal precio puede estimarse como el precio mínimo, mas se calcula un precio de exportación de referencia; dando lugar, a que, cuando los precios de exportación son superiores al mínimo, el exportador, en el caso de los países africanos, les paga la diferencia, mientras que en el caso brasileño, la autoridad nacional fija el precio de exportación, con lo que se persigue proteger al productor frente a variaciones desfavorables del precio. ${ }^{8}$

En cuanto a la estructura de comercialización externa, se observa una diferencia entre las importaciones de algunas empresas del Reino Unido que tienen representantes de compras en el África Occidental, y adquieren grandes cantidades directamente de las juntas de comercialización, mientras que otras empresas de ese mismo país, al igual que los grandes fabricantes de chocolate en Estados Unidos, compran en mercados terminales a comerciantes que importan cacao en bruto y disponen de existencias. Se da, de esta manera, una cadena de comercialización y distribución, que permite llegar a la conclusión que el menor beneficio lo percibe el pais productor, y el mayor, queda a lo largo del eslabonamiento que conduce, desde la compra, hasta la elaboración final del respectivo bruto puesto en mercado.

El objetivo central que algunos de los productores y los principa-

${ }^{7}$ Cf. Conferencia de las Naciones Unidas sobre Comercio y Desarrollo. Distribución general. Doc. TD 113-supp.3. 9 de febrero de 1972, p. 1.

${ }^{8}$ Ibid., p. 2. 
les países importaclores tenían en mente, era el de expeditar la conclusión de un acuerdo internacional sobre el cacao, tesis a la que se sumaron el grueso de participantes en la tercera reunión de la UNCTAD, como en efecto lo comprueba la resolución 49 (III) que instó a la convocatoria de una conferencia sobre el cacao para tal efecto. ${ }^{9}$

Los planteamientos de la Secretaría, dieron lugar, sin embargo, a un debate en el que intervinieron los países de economía dirigida, formulando, por su parte, otros, que merecen traerse a cuenta en estos comentarios, por estar directamente relacionados con el tema que venimos tratando. En efecto, y tomando para ello como referencia el estudio de FAO (situación y perspectivas de los productos básicos 1971-72), se lee lo siguiente ${ }^{10}$ :

"104. Las deliberaciones sobre esta materia, que se basaron en un informe provisional presentado por la Secretaría sobre el sistema de mercadeo del cacao, se concentraron en el mandato que ha de darse a la Secretaría de la UNCTAD para realizar estudios semejantes sobre otros productos. Por lo general, los representantes de los países en desarrollo recalcaron la gran importancia que sus gobiernos atribuyen a estos estudios, que en su opinión deben tratar de identificar la proporción del precio finalmente pagado por los consumidores que va a parar efectivamente a los países productores. Según los representantes de los países socialistas de Europa Oriental, el objetivo principal de tales estudios debe ser el de tratar de eliminar a los intermediarios innecesarios en las operaciones internacionales de mercadeo. Los representantes de estos dos grupos de países recalcaron también la necesidad de que se investiguen los efectos que ejercen las empresas multinacionales en los mercados internacionales de productos básicos. Los representantes de los países desarrollados declaraban que no se oponían en principio a la ampliación de este tipo de estudio a otros productos.

OUNCTAD - Tercer Periodo de Sesiones. Santiago, Chile, 29 de junio de 1972-. La Conferencia de las Naciones Unidas sobre Comercio y Desarrollo. Recordando su resolución 16 II de 26 de marzo de 1968; Recordando además, la resolución 2620.

${ }^{10} \mathrm{FAO}$, situación $\mathrm{y}$ perspectivas de los productos básicos, p. 28, párrafos No 104 y 105 .

El autor trae a cuenta el debate de la III UNCTAD, no sólo en relación a los problemas de comercialización de los productos básicos en sí, sino también, por lo que se refiere al control internacional de las empresas multinacionales, examinado por Francisco Orrego Vicuña, dada la estrecha interrelación existente, y por lo que no se explaya sobre este último tema, remitiendo al estudio de Orrego Vicuña. 
ESTUDIOS INTERNACIONALES

Estimaban, sin embargo, que era necesario primeramente terminar el estudio sobre el cacao y decidir después si estaba justificada la realización de otros estudios, teniendo en cuenta los recursos necesarios y la utilidad de los resultados probables. No se pudo llegar a ningún acuerdo para conciliar los puntos de vista de los países en desarrollo y los países socialistas por un lado, y de los países desarrollados por el otro. El proyecto de resolución presentado por los países desarrollados fue rechazado mientras el de los países en desarrollo fue aprobado por mayoría de votos.

105. El texto aprobado pide al Secretario General de la UNCTAD que prepare estudios completos sobre los sistemas de mercadeo y distribución de los productos primarios cuya exportación tiene interés para los países en desarrollo y que los presente a la Comisión de Productos Básicos. En estos estudios deben incluirse, entre otros, además del cacao los siguientes productos: té, bananos, tabaco, caucho, semillas oleaginosas, aceites y grasas, tortas oleaginosas, algodón, mineral de manganeso, antimonio y wolframio. Cada uno de los estudios deberá definir claramente lo siguiente:

a) La proporción de los ingresos totales procedentes de las exportaciones de esos productos que queda retenida en el territorio de los países en desarrollo;

b) Los efectos que ejerce el funcionamiento de los mercados de productos básicos en los niveles de precios y sus fluctuaciones;

c) Los elementos de carácter monopolístico y oligopolístico, incluidas las empresas plurinacionales, que influyen en los niveles de precios de los principales mercados mundiales de productos básicos y las consecuencias que de ello se derivan para los países en desarrollo."

El nivel de las discusiones, y la activa participación en ellas de los tres sectores integrantes del comercio mundial actual, pone de manifiesto que el problema en gran parte permanecexá irresoluble de no encontrarse mecanismos que aseguren a los productores una mayor participación en los beneficios del comercio, y que tal participación acrecenta en la medida en que, por una parte, aumente el poder de negociación de los productores, y por la otra, pueden manejar sus existencias o recursos naturales, con la eficacia y eficiencia con que lo manejan los componentes del eslabonamiento comercial hasta llegar al auténtico comprador o importador de grandes existencias. 
Si bien es cierto que el convenio sobre el cacao, al que finalmente se llegó en octubre de 1972, no resuelve la totalidad de los problemas planteados en la Conferencia de UNCTAD, el hecho es que tal instrumento constituye un jalón de envergadura en dirección de resolver los problemas que preocupan al Estado de los países del Tercer Mrundo. Más adelante, volveremos sobre este tema, ya que nuestro interés en traerlo a cuenta fue básicamente para correlacionar el problema de la merma de ingresos reales, con los nuevos sistemas de mercadeo y distribución de productos básicos.

En adición, creemos oportuno traer a cuenta otras modalidades que vienen en abono de la tesis de que el Estado se ve forzado o compelido a participar en estos procesos, para compensar crecientes disparidades y mermas en los ingresos, restableciendo así, el equilibrio táctico que originalmente se tenía en mente lograr, al darle participación a los países subdesarrollados, como productores, en los mecanismos internacionales del comercio mundial, y que, aparejan un aumento en la capacidad de negociación real de los propios países.

\section{$O P E P$}

Cabe precisar, en primer término, el caso de OPEP. Las modalidades de comercialización a nivel mundial de hidrocarburos y sus derivados nos revelan que los países productores pueden establecer conjuntamente, o en todo caso, un grupo importante entre ellos, mecanismos que les aseguran una mayor participación en los beneficios que se derivan precisamente de la comercialización al fijar precios de venta y acordar retenciones o liberación de cuotas. En este caso, juega un papel importante, si no determinante, la favorable coyuntura de ser los países miembros los principales proveedores, y los países desarrollados, los consumidores. Para ese efecto el Estado necesariamente tiene que intervenir más activamente, en el plano internacional, y nacional.

\section{Empresas nacionales}

El segundo lugar puede identificarse con la creciente tendencia del Estado a organizar instituciones de derecho público o de derecho privado a las cuales se confía la comercialización de uno o más productos básicos, para así aprovechar el poder de negociación del propio Estado, y el volumen de productos a la disposición de la entidad. Volumen, posibilidad de stocks asegurados, oportunidad 
y seguridad de entrega, constituyen, pues, los principales ingredientes del poder de negociación, que apareja por lo demás, una mayor participación de los países en los beneficios de la comercialización.

Este modelo, conocido no sólo en los países de economía dirigida o centralizada, sino también, en algunos de los países desarrollados, como Italia, por ejemplo, es utilizado no tanto en relación a la exportación, sino a la importación de determinados productos básicos considerados estratégicos para el desarrollo y la seguridad económica del país. El caso del ENI (Ente Nacional de Hidrocarburos), de sobra conocido en los medios académicos y comerciales, ilustra nuestra observación. Al analizarse el caso del ENI, que interviene y participa directamente en el comercio internacional de los hidrocarburos y gases industriales, así como en la producción que tiene lugar fuera de Italia, nos muestra cómo precisamente la intervención del Estado en el comercio internacional, ofrece múltiples ventajas al desarrollo interno, mas debe tenerse presente que estamos frente a una gama de productos considerados estratégicos para el desarrollo y la seguridad económica del pais. Desde luego, el caso del ENI, y algunos otros institutos paraestatales existentes en Italia (y también en Francia) no se reduce a este tipo de participación o intervención, sino alcanza la constitución y operación de otro tipo de empresas (de derecho público y de derecho privado) directamente relacionadas con la producción de bienes y servicios, algunos de los cuales se exportan al extranjero; mas en tales casos, las empresas en referencia actúan directamente como sujetos de derecho en este tipo de actividad, pero, las matrices, pueden, cuando así se estima en interés de su economía externa, manejar la exportación de tales productos (derivados de la petroquímica, por ejemplo).$^{11}$

Este modelo de empresa no queda reducido en sus posibilidades a un único país, dándose la posibilidad de formación entre dos o más países, particularmente, como medio para suprimir el conflicto derivado de la competencia.

\section{Los Institutos de Estabilización de Precios en Centroamérica}

En tercer lugar, conviene ilustrar el tema, con otro ejemplo del "mundo subdesarrollado". En el caso preciso del mercado Común Centroamericano, todo el régimen de granos básicos (Protocolo de Limón), está basado en el engranaje constituido por los Institu-

"2Véase la Ley Constitutiva del ENI -Ente Nazionale Idrocarburi-, Ley No 136 del 10 de febrero de 1953, reformada por Ley $N$ Q 1589 del 22 de diciembre de 1956, y Ley No 1153 del 14 de noviembre de 1967. 
tos o entidades estabilizadoras de precios, los únicos autorizados para efectuar importaciones desde terceros países, cuando la oferta regional es insuficiente para satisfacer las exigencias de uno o más países miembros. EI derecho del productor privado de cualquiera de los países miembros del mercado, es exportar a los restantes países miembros, sin limitaciones, más que las naturales exigencias de los Institutos de estabilización de precios, mas no puede exportar o importar fuera de la zona, ya que la competencia corresponde a tales institutos.

En efecto: Conforme al artículo primero del Protocolo de Limón (Costa Rica) al Tratado General de Integración Económica Centroamericana, suscrito el 28 de octubre de 1965, los Estados miembros regulan la comercialización e intercambio de granos básicos del área centroamericana, coordinan las políticas nacionales de producción y abastecimiento y aseguran la más amplia libertad de comercio, dentro del mercado común centroamericano, por lo que, conforme al artículo 3o:

"Los organismos de Estabilización de Precios serán los únicos que podrán efectuar importaciones de granos básicos de fuera de la región en condiciones preferenciales, salvo lo dispuesto en el art. $V$ (que se refiere a importaciones procedentes de fuera del área que se hagan por cada país, con carácter de donación").

Luego, el artículo $6{ }^{\circ}$ estipula:

"Los organismos de Estabilización de Precios, antes de negociar exportaciones o importaciones de granos básicos con países de fuera del área centroamericana, deberán efectuar consultas entre ellos. En la negociación de excedentes de granos básicos y para satisfacción de faltantes, Ios Estados signatarios tendrán prioridad sobre aquellos de fuera del área. Las exportaciones de granos básicos para terceros países podrán efectuarse libremente cuando no haya interés de compra por parte de Ios Estados Contratantes, manifestando dentro de un plazo prudencial que fijará en su oferta el país vendedor."

\section{Los Esquemas de Integración Económica}

La posibilidad de que distintos institutos nacionales constituyan una empresa para el manejo de este tipo de operaciones, a nivel del mercado internacional, no está excluida ni tampoco reñida 
con los presupuestos de la integración económica regional. El ejemplo centroamericano precisamente demuestra que una àdecuada política de abastecimiento y de crecimiento equilibrado, es no sólo imperiosa para los esquemas integrativos de países subdesarrollados, sino que es de responsabilidad del Estado, o si se prefiere, de instituciones autónomas o descentralizadas del Estado, y que la actuación conjunta de los Estados en ese plano, constituye una modalidad que asegura la viabilidad de tales objetivos.

Esta alternativa no puede descartarse sino por razones ideológicas, mas no por razones estratégicas, o invocando su incompatibilidad con la naturaleza y fines de la integración económica, ya que, por una parte, este tipo de mecanismo aumenta el poder de negociación del grupo frente a terceros países, que en sí, es uno de los motivos políticos que se aducen para la integración económica a nivel de países subdesarrollados, y por la otra, permite aprovechar las ventajas, cuantitativas y cualitativas que ofrece la actuación conjunta a través de una empresa. Por la otra, y esto es importante subrayarlo, tales mecanismos no desconocen las reglas imperantes en el comercio internacional, entre otras, la de la libre competencia, por cuanto están sujetas precisamente al juego de la competencia en ese plano.

Hasta el presente, las instituciones de Comunidades Europeas no han declarado incompatible con el Tratado de Roma, la comercialización a nivel interno de la comunidad o a nivel internacional con terceros Estados, de productos básicos o manufacturados por empresas estatales o paraestatales de algunos de los países miembros, $y$, en relación a países no miembros, se han visto compelidas a regular los efectos de tales modalidades, como lo confirma el reglamento de la Comisión del 19 de diciembre de 1969, por el que se estableció un régimen común aplicable a las importaciones de paises de comercio de Estado, y cuyo anexo fue ampliado o extendido a otras importaciones, por reglamento de junio de 1972 (D. O. 1151 del 5.7.1972).$^{12}$

${ }^{12} \mathrm{Cf}$. Boletín de las Comunidades Europeas, quinto año, No 8, 1972, pp. 108 y 109. Oficina Publicaciones Oficiales de las Comunidades Europeas, Luxemburgo. Acerca de los problemas legales resultantes del intercambio entre sistemas de comercio de Estado y de Mercado Libre, téngase presente que, por lo general, se da dentro del marco de tratados bilaterales, y sobre las bases de estricta reciprocidad. Hasta hace pocos años, la cláusula de la nación más favorecida no jugaba ningún papel; sin embargo, en la actualidad tal asunto está en proceso de revisión, desde el momento en que la Uunión Soviética busca replantear el juego de la cláusula en sus relaciones comerciales con Estados Unidos, para vencer algunos problemas legales que se presentan en Estados Unidos, por disposiciones restrictivas. Un detalle de los tratados bilaterales entre los paises de la CEE y el COMECON, puede encontrarse en TOLEDADO LAREDO, op. cit., ver nota No 4. En adición, véase: Pisar, Samuel, "TRANSACTIONS ENTRE L'EST ET L'OUEST". Ref: Le Monde-Selection Hebdomadaire, No 1283 (1973). 
El propio Pacto Andino ha contemplado, por su parte, un programa de armonización de los instrumentos de regulación del comercio exterior de los países miembros (art. 30, que incluso fijó plazo para ponerse en práctica antes del 31 de diciembre de 1972), y que puede dar lugar a la constitución de este tipo de estructuras. ${ }^{13}$

Por lo que al Mercado Común Centroamericano se refiere, es oportuno señalar a este mismo respecto las disposiciones expresas que los Estados Centroamericanos adoptaron al iniciarse el programa de integración económica. En primer término convinieron en no utilizar ni otorgar franquicias aduaneras a la importación procedente de fuera de Centroamérica, de artículos que se produzcan en cualquiera de los Estados contratantes, así como que en el caso de adquisiciones por el Estado, sus agencias, empresas y entidades descentralizadas se daría preferencia a la producción centroamericana; luego en dar una aplicación extensa al principio de la no discriminación, y finalmente, prever la contingencia de empresas constituidas o creadas por el Estado. El artículo IX del Tratado Multilateral de Libre Comercio e Integración Económica Centroamericana suscrito en 1958 estipula:

"Salvo lo establecido en los tratados bilaterales centroamericanos vigentes o lo que se convenga en nuevos tratados entre Estados Centroamericanos, las partes signatarias, con el propósito de dar extensa aplicación en sus relaciones comerciales al principio de la no discriminación, convienen en que:

c) Si uno de los Estados signatarios crea o mantiene una entidad o dependencia u otorga privilegios especiales de determi-

Los recientes tratados de comercio entre la Unión Soviética y algunos paises latinoamericanos, entre ellos, con Chile, Costa Rica, aparte de establecer plazos y volumen de comercio, conservan la tónica tradicional excluyéndose la aplicación de la cláusula por el hecho de que dichos países forman parte de esquemas de integración económica.

${ }^{1} \mathrm{El}$ art. 30 del Pacto Andino - Acuerdo de Cartagena- establece a este respecto:

"La Comisión, a propuesta de la Junta, acordará un programa de armonización de instrumentos y mecanismos de regulación de comercio exterior de los países miembros que será puesto en práctica por éstos antes del 31 de diciembre de 1972."

Luego, el artículo 89 -Asuntos Financieros-, prevé que la Junta presentará a la Comisión propuestas relacionadas con el financiamiento o financiación del comercio entre los países miembros y con los de fuera de la Subregión.

Entre los mecanismos a que se refiere el Acuerdo, figuran las empresas a constituirse por los países miembros, ya con carácter nacional o mixto;

En adición a lo anterior, es oportuno traer a cuenta los estudios que se han emprendido entre algunos países productores de café para establecer una empresa multinacional encargada de la comercialización de dicho grano, en el mercado internacional, tema que ha sido tratado en el seno de la OIC, aunque no como asunto propio de la órganización. 
nada empresa para atender exclusiva o principalmente, con carácter permanente o eventual, la producción, exportación, importación, venta o distribución de cualquier mercancía, dicho Estado concederá al comercio de los otros Estados signatarios un tratamiento equitativo con respecto a las compras o ventas que la entidad, dependencia o empresa mencionada haga en el exterior. La institución de que se trate actuará como una firma comercial privada, ofreciendo razonablemente al comercio de los otros países la oportunidad de competir en tales operaciones de compra o de venta."

\section{La comercialización a nivel de productores y consumidores}

EI texto de las resoluciones y decisiones de la tercera UNCTAD ${ }^{44}$ conducen a que la comercialización y mejor distribución de beneficios demanden, por su parte, medidas a tomarse no sólo a nivel de productores - el comercio de Estado, o a través de empresas estatales o paraestatales- sino a nivel de importadores o consumidores, cuyos sistemas económicos pueden o no acomodarse a similares variantes.

Tales medidas reclaman, por lo tanto, instrumentación mediante convenios internacionales de tipo abierto. Las ventajas y los hechos condicionados aun permiten que los países se inclinen por esta fórmula. El caso del cacao, nuevamente traído a cuenta, nos muestra las actuales tendencias.

En efecto: el objetivo del acuerdo suscrito a fines de 1972, después de insistentes presiones de los directamente interesados, tiende a (art. 1):

a) aliviar las graves dificultades económicas que persistirían en el caso de que el ajuste entre la producción y el consumo del cacao no pudiere efectuarse por la acción exclusiva de las fuerzas normales del mercado con toda la rapidez que las circunstancias exigen;

b) prevenir las fluctuaciones excesivas del precio del cacao perjudiciales para los intereses a largo plazo, tanto de productores como consumidores;

c) tomar disposiciones que ayuden a estabilizar o incrementar los ingresos que los países productores obtienen de las exportaciones del cacao, contribuyendo así a proporcionar a esos

1“"La Estrategia del Tercer Mundo"; Véase, para el efecto las Resoluciones de la III UNCTAD, Nos. 46 (III) ; 54 (III) ; 58 (III); 82 (III). 
países recursos para acelerar su expansión económica y su desarrollo social, y teniendo en cuenta al propio tiempo los intereses de los consumidores en los países importadores;

d) garantizar un suministro adecuado a precios razonables y equitativos para productores y consumidores;

e) facilitar la expansión del consumo, y, de ser necesario, y en lo posible, un reajuste de la producción, de modo que se asegure el equilibrio a largo plazo entre la oferta y la demanda.

$\mathrm{El}$ instrumento en referencia, si bien se ciñe en líneas generales a los puntos sobresalientes de otros de la misma índole, café y azúcar principalmente (sistemas de cupos básicos, redistribución del déficit; voto ponderado, etc.), por su parte incorpora nuevos elementos de regulación sobre precios, cupos básicos, cupos anuales de exportación, alcance de los cupos de exportación, reajuste y observancia de cupos, redistribución de déficits, reservas de estabilización, compras y ventas de las reservas de estabilización para defender, no el precio mínimo, sino el precio máximo, retiro de reservas, cambios en paridades de monedas, seguridades de suministro, transferencia de usos no tradicionales, y medidas de control en cuanto a exportaciones e importaciones.

En esta misma forma, el convenio contempla algunas fórmulas para reducir obstáculos a la expansión del consumo, y los sucedáneos del cacao, con la consiguiente limitación de las importaciones procedentes de los países no miembros y las transacciones comerciales con los no miembros.

El mecanismo de la reserva de estabilización, va mucho más lejos que otros conocidos hasta la fecha, por cuanto se asegura el compromiso de mantener una capacidad máxima de 250.000 toneladas, siendo responsable del funcionamiento de la reserva, de las operaciones de compra y venta, y buen mantenimiento de la misma, así como renovación de las partidas, un Gerente de reservas, responsable ante la organización instituida por el convenio, debiendo a tal efecto actuar de acuerdo con las normas aprobadas por el Consejo.

El financiamiento de las operaciones, cuenta con ingresos asegurados desde el inicio, mediante ingresos regulares en forma de contribuciones sobre el cacao fijadas en el convenio (art. 37 inciso 4, y art. 38)

No es nuestro propósito en estos comentarios glosar el convenio, sino traer a la atención del Grupo de Estudio que en el caso del cacao, los países productores y consumidores dieron una serie de pasos adelante en cuanto a una mejor comercialización de este producto básico, y asegurar una mayor participación de los productores en los beneficios derivados de esa comercialización. Paralelamente, 
sin embargo, muchos de los países productores y consumidores, que intervinieron activamente en este convenio, e igualmente en la discusión sobre la "vida y suerte" del convenio del café, se abstuvieron de orientar la nueva política del café por similares senderos al cacao. El fenómeno de la dispersión y de distintas estrategias, según sea el producto, aparece de consiguiente en forma visible. Sea cual hubieren sido las razones tácticas para no abordar el problema del café, en similar forma como el cacao, el hecho es que un solo país latinoamericano -Brasil- con fuerte y determinante participación en el mercado de ambos productos, confronta situaciones totalmente distintas según se trata de uno y otro producto, hecho que, en un caso -el café-, apareja beneficios temporales para los otros productos latinoamericanos, y en el del cacao, una estabilización estratégicamente útil para sus intereses. ${ }^{15}$

Cabe de consiguiente formularnos la pregunta, si realmente puede haber o no una estrategia común para los productos básicos, o si las actuales y futuras exigencias de los países latinoamericanos, los mueven a distintas estrategias, producto por producto; a un sistema de mercado abierto libre de mayores regulaciones en un caso, y en otro, enteramente sometido a controles para garantizar el equilibrio.

El hecho es que, la evidencia apunta en dirección de una disciplina común entre productores y consumidores, según la naturaleza y sensibilidad del producto, y no una política común aplicable a los productos básicos. Esto deja, a cada país, en mayor libertad de defender sus propios intereses, a menos que el problema se aborde desde otro ángulo: el de esquemas de integración económica que puedan moverse en dirección de políticas comerciales unificadas, o en todo caso, coordinadas debidamente. En cierto sentido, la adversa situación que confrontan los países latinoamericanos no es resultante exclusivamente de los patrones y reglas actuales del comercio internacional, o de una desequilibrada participación, sino del tipo y alcance de las distintas estrategias que sigue cada país, y todos en conjunto, frente al resto del mundo.

"Véase a este respecto: FARRER, Tom $J$. "ECONOMIC DEVELOPMENT AGREEMENTS: A FUNCTIONAI ANALISIS", Colombia Journal of Transnational Law, Vol. 10, Ne 2, Fall 1971; MENDOZA, José Luis, "¿Habrá un Nuevo Convenio Internacional del Café?", Guatemala, 1972. 


\section{ALINEACIONES Y APROXTMAGIONES}

El fenómeno de la asociación de un cleterminado esquema de integración económica si bien es reciente, no es del todo desconocido en la actualidad. Tampoco es necesario traer a cuenta estrategias de tipo neocolonialista por parte de los países europeos miembros de la CEE para interpretarlo en correcta perspectiva, sin desconocer, que en sus origenes, hubo mucho de este tipo de estrategia. Sin embargo, la variante de Estado Asociado a un determinado esquema de integración, abre puertas para resolver muchos de los problemas que aquejan a los países en vías de desarrollo, con sistemas de economía de mercado o de economía planificada. El caso de los países africanos asociados a la Cee, de Grecia, Turquía, y algunos otros, puede traerse a cuenta, así como también puede invocarse la gestión de Rumania y de Yugoslavia de establecer lazos más definidos con la CEE.

La política de las preferencias abiertas a los Estados Asociados de la CEE tampoco puede negarse que constituye una modalidad valiosa para ellos, por cuanto, paralelamente, disfrutan de las preferencias que otros países desarrollados conceden a los países del Tercer Mundo. De esta manera, frente a Estados Unidos, Canadá, Japón, los países escandinavos, los Estados Africanos asociados a la CEE cuentan con un radio más amplio y flexible de preferencias que los países latinoamericanos. Estos últimos, careciendo de vínculos institucionalizados con la CEE, se ven compelidos a aceptar las reglas de juego a ese nivel, pese a que han contado con estructuras regionales susceptibles de superar esa situación desfavorable frente a los países africanos.

Nuevamente se plantea similar problema; esta vez, sin embargo, con proyecciones muy distintas. La actual CEE está constituida por nueve países, que en conjunto, participan en el comercio internacional en posición ventajosa sobre Estados Unidos, la Unión Soviética, Japón y otros países industrializados. La fórmula de "asociación", tiende a desplazarse en dirección de arreglos que caen dentro de los marcos de la integración, y con lo que se excluye la aplicación automática de la cláusula de la nación más favorecida. Esta nueva modalidad, ofrecida a los países africanos asociados, y, a los países del Caribe que disfrutan de preferencias con el Reino Unido, implica la creación y extensión de una zona de libre comercio, y conlleva una nueva modalidad de alineación económica, que no presenta las mismas características y limitaciones de las alineaciones politicas, 
que condujeron a la creación de un bloque de países no alineados, y a la filosofía del neutralismo. Esta última, correspondió a una etapa de guerra fria, y ha perdido en mucho su sentido y significado frente a las nuevas exigencias de orden económico. De esta manera, un país africano puede encontrar, no un acomodo en la CEE a sus problemas y exigencias económicas, sino una ubicación en un contexto económico, que no le limita su capacidad de maniobra politica en relación a las dos grandes potencias mundiales, ni lo reduce a una alineación política con la Europea de los 9, sino le deja libertad de establecer sus propias relaciones económicas y políticas con otra potencia, como la República Popular China, o Japón.

En efecto: la Comisión de las Comunidades Europeas, en abril de 1973, aprobó proponer a los países africanos asociados a la CEE, una nueva convención, a suscribirse antes de la expiración del convenio de Yaoundé, cuya negociación se iniciará a partir del primero de agosto de 1973, e incluirá a los países del Caribe y del Pacífico que tienen aún en vigor el régimen de preferencias con el Reino Unido. El nuevo modelo está basado en el principio de una zona de libre comercio, que conlleva una ayuda financiera y tecnológica substancial, y un nuevo elemento de estabilización de ingresos resultantes de las exportaciones de algunos productos básicos, y de los cuales las economías de estos países son principalmente dependientes. ${ }^{16}$

El régimen de libre cambio asegura el mantenimiento del carácter contractual de las relaciones, a la par que contribuye a la atenuación o supresión de los desequilibrios resultantes de fluctuaciones de precios, y de las calidades de los productos básicos. La Comunidad por ende, les garantizará la estabilidad de los beneficios resultantes de ese comercio, principalmente en lo que concierne al azúcar, arácnidas, aceites de arácnidas, cacao, banano, café y cobre. La ayuda financiera, por su parte, implica un compromiso unilateral por parte de la Comunidad a favor de los países asociados al régimen de libre cambio señalado. ${ }^{17}$

${ }^{16}$ Propuestas de la Comisión de las Comunidades Europeas -Le Monde, 6 de abril de 1973-. La propuesta convención de asociación entre la Comunidad Económica Europea y los países del África situados al sur del Sahara deberá estar fundada sobre el principio de una zona de libre cambio, comportar una ayuda financiera $\cdot y$ técnica substancial $y$, elemento nuevo y fundamental-de estabilización de beneficios que les procura su exportación de algunos productos básicos, cuya economia resulta particularmente dependiente... Este documento representa una primera contribución a la preparación de una futura negociación curoafricana. Esta deberá abrirse como está previsto el 18 de agosto de 1973, es decir, diez y ocho meses antes de la expiración de la segunda-convención de Yaoundé.

${ }^{27}$ Propuestas de la Comisión de las Comunidades Europeas: Ibid. La Comunidad ofrece a sus asociados africanos una garantía de estabilidad de sus beneficios derivados de sus exportaciones. Resulta claro que las disminuciones tarifa- 
El nuevo régimen, viene, pues, a modificar sensiblemente el de preferencias existente hasta la fecha, ampliándolo al goce y disfrute de los beneficios del libre intercambio, y las ayudas previstas. El radio económico-político de la Comunidad se amplía, por una parte en sentido geográfico, y por la otra, se estabilizan las relaciones económicas con dichos países del Tercer Mundo, dentro de un marco legal diferente hasta el ahora conocido.

Resultante o no del descontento de los países africanos con la tercera UNCTADi18 y de un fenómeno de expansión de la Comunidad, el hecho es que los países latinoamericanos se ven orillados, en una u otra forma, a buscar arreglos similares con la potencia rectora del continente, o alternativamente, a diversificar sus enlaces comerciales para evitar verse alineados con dicha potencia, en mayor extensión de lo que a la fecha están.

El Tercer Mundo hace, pues, frente a un nuevo fenómeno en el campo de las relaciones económicas internacionales. La tendencia a la alineación presenta nuevas proyecciones así como la estrategia de la diversificación. En relación a esta última, no puede ignorarse una primera aproximación de parte de algunos países latinoamericanos con la CEE. El tratado suscrito por Argentina con la CEE parece ser la piedra angular de esa diversificación, senda seguida por Uruguay y Brasil. MLéxico, por su parte, busca mayores entre-

rias que han acompañado las grandes negociaciones internacionales, así como la puesta en vigor del sistema de preferencias generalizadas, han dado como resultado una disminución sensible de las ventajas tarifarias de las que se benefician los países asociados sobre el mercado de la Comunidad. De consiguiente, la nueva fórmula, o en todo caso, esta nueva aproximación al problema resultará en una mejor estabilización y más fuerte crecimiento de sus ingresos derivados de las exportaciones.

${ }^{18}$ Por lo que se refiere a las reacciones del Tercer Mundo acerca de la III UNCTAD, es ilustrativo que algunos países africanos expresaran su desaliento, al igual que los países latinoamericanos, cuyas espectativas, quizás eran mayores que las de los africanos.

La Conferencia Parlamentaria de Ia Asociación CEE-EAMA por ejemplo, en el transcurso de la reunión de 29 de mayo - 19 de junio de 1972, en Luxemburgo, de la Comisión Parlamentaria, examinó los trabajos de la UNCTAD, los que influyeron sus deliberaciones. Los parlamentarios coincidieron que el problema del desarrollo se había planteado mal en esa conferencia, al confrontar el conjunto de los países Ilamados ricos y el conjunto de los paises llamados pobres, lo que dio lugar a que las actitudes se alinearan alrededor del denominar más sencillo. Los escasos resultados de la Conferencia de Santiago, dieron lugar, entonces, a considerar que la Asociación entre la Comunidad Económica Europea y los paises africanos asociados, cobre y adquiera una "importancia confirmada", siendo necesario o conveniente en todo caso, reforzar la cooperación regional dentro de la Asociación, sin abandonar por ello las soluciones mundiales cuando se consideren posibles. Mayores detalles en: Boletin de las Comunidades Europeas, $5^{\circ}$ año, No 8, 1972, pp. 97-98. 
lazamientos con el Mercado Común Centroamericano y el Grupo Andino, a la par que se asegura la diversificación de relaciones económicas, mediante aproximaciones políticas con China Popular, los países socialistas, y la propia Comunidad Económica Europea, sin atenuar en forma alguna, sus estrechas relaciones económicas con Estados Unidos, y dando con ello, una impresión de realismo politico, que le traerá beneficios económicos en diversos planos.

El resto de países latinoamericanos, que cuentan con esquemas de integración económica (nos referimos a los países miembros del Pacto Andino y el Mercado Común Centroamericano) son poseedores de un mecanismo de negociación mayor si lo ejercen conjuntamente que aislada e individualmente.

La reciprocidad y el bilateralismo son reglas de juego con un sector de países (los del campo socialista), mas tales reglas están en proceso de revisión, desde el momento en que Rumania y Yugoslavia se aproximan directamente con la CEE y Hungría manifiesta su propósito de acceder al GATT. La cláusula de la nación más favorecida no opera automáticamente o en forma adversa al comercio entre países que cuentan con mecanismos de libre comercio, y como lo sostuvimos en nuestro estudio acerca de la cláusula en el marco del mercado común centroamericano, tampoco juega tratándose de aproximaciones entre esquemas de integración económica. ${ }^{19}$

Por otra parte, no puede hacerse abstracción del hecho que las aproximaciones comerciales por una parte, entre la Unión Soviética y Estados Unidos, y la Comunidad Económica Europea y los países miembros del COMECON, por la otra, tienden a intensificarse, dando lugar a nueva dicotomía en el plano mundial, apuntada con acierto por Samuel Pisar. Las transacciones comerciales entre el Este y el Oeste revelan una tendencia en dirección de arreglos bilaterales URSS-USA, y CEE, países de la Europa Oriental, al punto que el Tercer Mundo, y en particular, los países latinoamericanos, harán frente en el futuro inmediato a posibles sociedades de carácter "transideológico"20 cuyas primeras posibilidades se dan a raíz de las modificaciones de las legislaciones húngara, yugoslava y rumana; tendencia que también examina Polonia.

En otros términos, se tiende en el marco de los países desarrollados del Este y el Oeste a encontrar nuevas fórmulas de organización empresarial que coadyuven a intensificar los vínculos comerciales

${ }^{12} \mathrm{La}$ cláusula de la nación más favorecida en el Mercado Común Centroamericano. En "América Latina y la Cláusula de la Nación más Favorecida", Francisco Orrego Vicuña, editor; Dotación Carnegie para la Paz Internacional, Santiago de Chile, 1972.

soLe Monde, NQ 1283. Mayo 1973. 
entre los países miembros de distintos esquemas económicos y politicos a manera de salvar los escollos que presenta el comercio de Estado.

A la luz de las tendencias que hemos esbozado y que se observan a nivel de países desarrollados consideramos oportuno reiterar la tesis de la aproximación entre esquemas propiamente latinoamericanos, y de éstos, con los existentes en otras latitudes, a manera de equiparar beneficios entre los países del Tercer Mundo.

El estudio de los regímenes legales acerca de los productos básicos, conduce, pues, a una globalización de intereses, estrategias y alternativas, a efectos de no vernos conducidos al aislamiento que provoca la diversidad de regímenes reguladores de tales productos. Situados dentro de esta perspectiva, la perspectiva globalista, resulta entonces oportuno recapitular sobre los principales elementos examinados a guisa de conclusiones; luego, correlacionar las observaciones con las tendencias institucionales en las relaciones comerciales internacionales, y con los fenómenos expuestos y analizados.

\section{CONCLUSIONES SOBRE PRODUCTOS BÁSICOS}

1. La organización del mercado mundial revela tendencias sectoriales, y no en dirección de un régimen común, aplicable al grueso de productos, que obedece a la sensitividad en el mercado mundial de los distintos productos.

2. La organización del mercado, a nivel de productores, está condicionada por la naturaleza del producto, la exclusividad de la participación en el comercio mundial de un número reducido de países y un control entre ellos sobre la producción; de ahí la posición adversa de los países importadores.

3. La organización del mercado a nivel de consumidores no se presenta dentro de estructuras intergubernamentales, sino básicamente, a nivel de empresas multinacionales, lo que plantea al Tercer Mundo el problema del control y/o regulación internacional de las mismas para la defensa de sus intereses.

4. Los mecanismos de regulación de producción y comercialización de producto por producto revelan un pluralismo convencional, $y$ diversidad de estrategias.

5. La intervención del Estado en los mecanismos del comercio mun- 
dial, ocurre tanto a nivel de la organización de ese mercado como en su operación, aun cuando, en el caso de esta última, no prevalece una modalidad directa de comercio de Estado, sino una participación del Estado, dependiendo del productor.

6. La variante del comercio de Estado directo, entre Estados, mantiene en vigencia las reglas clásicas del bilateralismo y la reciprocidad, y se da principalmente por la búsqueda de nuevos mercados.

7. La variante del comercio de Estado, de tipo indirecto, por el contrario, se da dentro del marco del mercado regulado, adoptando la modalidad de organizaciones empresariales, que aprovechan los factores de eficiencia y el poder de negociación del propio Estado.

8. La intervención del Estado, en el plano nacional, tendiendo a asegurar el cumplimiento de sus compromisos internacionales, sobrepasa la ejecución meramente normativa del tratado o convenio, para abarcar la programación del desarrollo; pero, a su vez, depende de:

a) - sensibilidad del producto

b) - la estructura real del poder en cada país

c) - el papel del o de los productos en la balanza de pagos.

9. La comercialización de los productos básicos muestra tres elementos:

a) - el excesivo peso de las empresas multinacionales;

b) - ineficiencia de las organizaciones empresariales privadas de los propios países productores; y,

c) - tendencia a la comercialización por empresas estatales o paraestatales.

LOS PRODUCTOS BÁSICOS, Y LAS ESTRATEGIAS DEL TERCER MUNDO

1. En el contexto de teoría y realidades del comercio internacional, predomina una tendencia a la dispersión, que a su vez, orienta la formación de subgrupos, que toman la forma de esquemas de integración económica: ejemplos: Grupo Andino, Mercomún Centroamericano, CARIFTA, Comunidad del Africa Oriental, Grupo Magreb, Arreglos en Asia, etc;

2. La dispersión, lleva a su vez, independientemente del fenómeno de la formación de subgrupos, a la diversidad o pluralismo de regi- 
F. Tillagrán Framer / Mecanismos de regulación internacional de productos básicos

menes de comercialización de productos básicos y manufacturados en el plano internacional;

3. La dispersión, que conduce al pluralismo de regímenes de comercialización, apareja, en adición, nuevas alineaciones económicopolíticas que alteran la composición y estrategias del Tercer Mundo; pero, como contrapartida, permiten un retorno a la globalización de intereses;

6. Tanto la dispersión que conduce al pluralismo de regímenes comerciales, como la que apareja nuevas alineaciones económicas, en conjunto, no han debilitado, sino fortalecido, la capacidad de negociación de los países componentes del Tercer Mundo, así como, han orientado la participación de estos países, no sólo a nivel formal sino material en el plano mundial y regional.

7. El aumento en la capacidad de negociación de los países del Tercer Mundo, y en el grado de participación real, ha corrido parejo con el aparecimiento, en la escena internacional, de las empresas multinacionales, y las nuevas modalidades de operación de las mismas.

El Tercer Mundo, hace frente, pues, a problemas que afectan, no sólo sus relaciones formales con otros Estados del mundo desarrollado, sino, con empresas multinacionales, que tienen, con frecuencia, mayor poder económico que los países mismos, individualmente; al trasladar estos fenómenos al campo jurídico, y teniendo presente no sólo el carácter formal, sino material, del Derecho Internacional, resultan las siguientes cuatro tesis jurídicas:

\section{DERECHO INTERNACIONAL ECONÓMICO Y EL TERCER MUNDO}

I Tesis: EI Derecho Internacional ha sido más producto de una participación formal de los países subdesarrollados, que material, al grado que se le consideró como una estructura de imposición de los países desarrollados sobre los subdesarrollados, algunos de los cuales, al nacer a la vida independiente, se vieron compelidos a aceptar esa situación normativa.

II Tesis: A partir del fenómeno de la aparición y fortalecimiento del Tercer Mundo, las tendencias que se registran en el terreno fáctico -cohesión y dispersión-, muestran que la participación de los países del Tercer Mrundo en la construcción y/o revisión del Derecho 
Internacional, tiende más a ser material que formal, y que interesa más a la mayoría de Estados este tipo de participación que la meramente formal.

III Tesis: El Derecho Internacional Económico, es producto, pues, de grados variables de confrontación entre los tres mundos, más que de interacción, asegurando la norma adoptada, como consecuencia de ese proceso, mayor grado de consenso.

IV Tesis: El nuevo Derecho Internacional Económico, no es, por lo tanto, ajeno al proceso que tiene lugar en el campo fáctico, y por lo que se caracteriza por la sectorialización de regulaciones que determinan, derechos internacionales particulares. El común denominador de estos derechos internacionales especiales, es la teoría general del Derecho Internacional, y los elementos formales que caracterizan al Derecho Internacional. Estos regímenes especiales, constituyen un medio más eficaz de participación del Tercer Mundo en la construcción del nuevo Derecho Internacional Económico. 